\title{
Editorial
}

\section{Public participation and the protection of biodiversity in the Asia Pacific region}

\section{APJEL IN THE ASIA PACIFIC REGION}

This is the third year of publication of the Asia Pacific Journal of Environmental Law $(A P J E L)$ under the ownership of Edward Elgar. This is also the year in which $A P J E L$ will grow, as planned, from a single issue to two issues per year. Over the past three years APJEL has published articles that have engaged with environmental law issues across many jurisdictions in the Asia Pacific region, including China, India, Indonesia, Japan, Singapore and South Korea. We look forward in future issues to expanding further the geographical reach of the research that APJEL publishes on environmental law issues in this dynamic region. We remain extremely pleased by the level of interest in APJEL and the many high quality submissions that we receive.

We are also delighted to advise that APJEL has recently been accepted by Clarivate Analytics into the Emerging Sources Citation Index (ESCI), and will be indexed and abstracted in that Index.

In this issue APJEL features three articles which have general relevance for readers across the region and which draw from case studies from Australia, Indonesia and Japan.

\section{THE ARTICLES IN THIS ISSUE}

Evan Hamman's article aims to provide some insight into the relationship between people and wildlife in the context of environmental law. The article considers the attitude of the Japanese people toward birdlife and toward wetlands and toward environmental law. A case study of the Japanese 'red-crowned' crane (the tancho) and of Ramsar sites in Eastern Hokkaido is presented, in order to examine Japan's environmental governance systems and actors and the extent to which they utilize the principle of public participation. Wetlands and birdlife are being lost in East Asia at a rapid rate, and the impacts that such losses may have on communities and on national identity are considered. The issue is not unique to Japan-neighbouring Asian countries like China and Korea, both of which have their own cultural perceptions and legal protections to consider, face similar realities. Australia, which has bilateral conventions relevant to birdlife with all of these three Asian countries should be interested - as should be any of the 170 contracting Parties to the Ramsar Convention on Wetlands of International Importance, 1971. Wetlands, as Hamman explains, have a vital role to play in the preservation of biodiversity and the provision of ecosystem services to human beings. In achieving the object of preserving biodiversity so that such ecosystem provision may be maintained, it is crucial that there be public participation-both of relevant local 
communities and of state populations as a whole. Hamman demonstrates through his case study how essential educating people and harnessing them in conservation efforts is.

The theme of harnessing public participation continues in the next article in this issue, by Bridie Butterfield. In recent years there have been a number of instances of 'ordinary' people making efforts through their judicial systems to hold their national governments to account for their efforts (or lack thereof) in addressing climate change. Notably, public interest litigation in the Netherlands (the Urgenda case) and in the United States (the Juliana case) have focused attention on this possibility. The potential of litigation to influence government decisions with respect to mitigating the damaging impacts of climate change may soon be tested in many more states. Butterfield's article considers the role of mitigation in the Paris Agreement, 2015, highlighting the gap between the climate change-related goal which the Parties have collectively agreed to support, and what she argues is the virtual impossibility of this goal being achieved on the basis of the Parties' individual non-binding commitments (as these have been outlined to date in Parties' Nationally Determined Contributions). In the light, she explains, of effective international solutions being slow to eventuate, it is important to consider the potential role of climate change litigation in promoting positive climate outcomes. Finally, Butterfield raises the prospect of the Australian government being held accountable in its national courts for what Butterfield contends to be the government's relative inaction on climate change. She makes reference to the potential influence of international judicial activism, and to Australia's international obligations (under the 1992 UN Framework Convention on Climate Change, the 1997 Kyoto Protocol, and the 2015 Paris Agreement), and considers how these might be used to give greater legal force to limiting the country's collective emissions.

The third article is by Laely Nurhidayah, and takes in themes also of public participation and the protection of biodiversity. Comparing Indonesia and Australia, the author writes that there are strong indications that marine biodiversity has been deteriorating in both countries - and of course globally. Losses of marine diversity, she explains, are largely as a result of conflicting uses of coastal habitats, land-based marine pollution, destructive fishing practices, illegal, unreported and unregulated (IUU) fishing, overfishing, the impact of invasive alien marine species, and climate change. This article examines marine biodiversity laws in Indonesia and Australia, considering particularly the implementation of the 1992 Convention on Biological Diversity in domestic legal frameworks. The article concludes that although laws are in place in Indonesia and Australia to conserve, and promote sustainable use of, marine biodiversity, there are many challenges to effective implementation of the legal framework in both countries. While in Indonesia the prominent challenge is integrating marine conservation and food security; in Australia, one of the most significant challenges is tackling the impacts of climate change on coral reefs. Lessons can be learned from the experiences of both countries to enhance the protection of biodiversity in marine environments worldwide.

\section{COMMENT}

This remains an exciting time for environmental law scholarship in the Asia Pacific region, and we are confident that $A P J E L$ will have an important role to play in enhancing this scholarship. As always, we welcome ongoing contributions toward 
understanding both the regional dynamics of environmental law and the particular experiences of different countries within the region.

Ed Couzens and Tim Stephens Editors, The University of Sydney Law School, Australia

Saiful Karim

Associate Editor, Faculty of Law, Queensland University of Technology, Australia 